\title{
A follow-up study observing health outcomes of the care recipients in the home and community-based service of the long-term care system of Taiwan
}

\author{
Li-Fan Liu' ${ }^{*}$, Nai-Wen Guo ${ }^{2}$, Pei-Fang Su ${ }^{3}$ and Jia-Jen Chen ${ }^{4}$ \\ ${ }^{1}$ Institute of Gerontology, College of Medicine, National Cheng Kung University, Tainan, Taiwan \\ ${ }^{2}$ Institute of Behavior Medicine, College of Medicine, National Cheng Kung University, Tainan, Taiwan \\ ${ }^{3}$ Department of Statistics, National Cheng Kung University, Tainan, Taiwan \\ ${ }^{4}$ Institute of Gerontology, College of Medicine, National Cheng Kung University, Tainan, Taiwan
}

\begin{abstract}
Background: In planning for the country's long-term care provision, the Taiwanese government launched the long-term care policy since 2007. There is a need to observe the follow-up health outcomes of care recipients and provide feedback to policy and practice.

Purpose: This study explored the health outcomes of LTC recipients in the home and community-based service by following the changes in outcomes for two years, and examined the factors associated with.

Methods: The data came from the long-term care dataset (LTC-CM) of one southern city in Taiwan for people with LTC needs. In total, 1,338 care recipients who were reassessed by care managers from the baseline to two years (T0-T4) in the dataset were analyzed. The descriptive and inferential analyses were conducted. Generalized Estimating Equations (GEE) were used to analyze four universal outcome measures, including the activities of daily living (ADLs), the instrumental activities of daily living (IADLs), the Short Portable Mental Status Questionnaire (SPMSQ), and the short version of the Centre for Epidemiologic Studies Depression Scale (CESD).

Results: Different patterns were found with regard to the changes in outcomes of the care recipients and their characteristics that influenced these changes. The ADL scores increased from T1 to T3 (OR from T1-T3=1.27 to $1.21, p<0.01$ ) when compared with T0. The IADL scores fell from T1 to T4 (OR from T1-T4=0.75 to $0.66, p<0.001)$. The average cognitive status decreased in T4 compared with T0 (OR $=0.85, p<0.001)$. In contrast, the CESD outcomes increased (OR from T1-T4=0.73 to $0.55, p<0.001)$. Age, gender, living status, educational level, social welfare status and the dependency level at baseline (T0) significantly influenced the change of health outcomes.

Conclusions/Implications for practice: This research found that the patterns of changes in outcomes moved in different directions. The tendency of depression among care recipients had changed more positively. Exact monitoring and feedback of the health outcomes of care recipients are needed to effect improvements in policy and long-term care service practice.
\end{abstract}

\section{Introduction}

\section{The long-term care policies and service delivery}

With the trend of population aging, the long-term care need is increasing rapidly in Taiwan. In planning for the country's LTC provision, the Taiwanese government launched the LTC 1.0 policy in 2007, aimed at helping frail elderly people with LTC needs, including the elderly aged 65 and over, people aged 50 and over with a disability certificate, and aboriginals aged 55 and over [1]. To facilitate service delivery and reform the LTC policies, the government began transitioning to the development of a new LTC 2.0 policy as of 2016. Apart from institutional care, the LTC policy in Taiwan is aimed at developing home and community-based services (HCBS), such as home services, adult day care, home nursing care, home and community-based rehabilitation, home meal delivery, palliative care for caregivers and transportation services. Based on the household social welfare status, the LTC recipients need to co-pay $30 \%, 10 \%$, and $0 \%$ of the LTC service charges for non-low, mid-low, and lowincome households, respectively, and the financial subsidies are mainly provided by the central government. The broad aim is to develop costeffective and efficient ways of coordinating services in order to improve the quality of life [2].

\section{Need assessments for receiving formal LTC services}

Multiple instruments from a national standardized questionnaire issued by the Ministry of Health and Welfare are used in need assessments, with a broad range of questions regarding physical health, mental health and functional ability. Based on this questionnaire, the

Correspondence to: Li-Fan Liu, Professor, Institute of Gerontology, College of Medicine, National Cheng Kung University, Tainan, Taiwan, Tel: +886-62353535, Etn: 5730; Fax: +886-6-3028173; E-mail: lilian@mail.ncku.edu.tw

Key words: health outcomes, home and community-based service, long-term care (LTC)

Received: September 20, 2017; Accepted: October 09, 2017; Published: October 12,2017 
care managers identify LTC recipients' dependency levels in a single assessment process into three levels, mainly according to the difficulty of the items in the activities of daily living (ADLs) [3]. The LTC dataset has to be also maintained by care managers in the care management system, from the initial needs assessments to each reassessment that takes place every six months during home visits. By using the same national standardized questionnaire, care managers are able to monitor clients' health status and changing needs, and this approach is to maintain or possibly improve care recipients' health outcomes to reach the goal of maximizing their functional independence.

\section{The outcome changes of care recipients in the HCBS}

In long-term care, finding evidenced based and effective strategies to manage chronic diseases and conditions is essential. Although the national long-term care system in Taiwan has been used to overcome the fragmentation resulting from the decentralization of the LTC system to the municipal level, there are few evaluations of it. Needs assessments are one of the most important core tasks of care managers in Taiwan, as they determine clients' subsequent care plans by using the information obtained in the initial assessment. Although the care recipients need to be reassessed every six months under government regulations, the results are not necessarily analyzed, and therefore there is a lack of information regarding the outcome changes of care recipients under HCBS approach. Examining the health outcomes of care recipients is a critical step for planning and quality improvement purposes, and it is also useful to measure performance at different levels, such as the individual, community levels, county and state levels [4].

As Kruk and Freedman [5] noted, evaluations of the effectiveness of health care systems tend to focus on health status and patient satisfaction (outcomes), as well as on access and quality of care (outputs). In view of the rapid expansion of the LTC service network and increasing use of such services in Taiwan, it is important to obtain information on the changing health status of care recipients by following up their health outcomes, as these are indicators related to physical and mental functions at the individual level. However, there is a gap in the current literature with regard to this context, especially in terms of the changes in health outcome based on the information obtained in reassessments.

\section{The universal outcome indicators}

Previous studies have shown that "universal" outcome measures, such as general health, ADLs, IADLs, cognitive status, depression, resident satisfaction, and quality of life, are needed across diseases, and that outcome measures can be applied to quality improvement and to determine payments $[4,6]$. Therefore, apart from the physical functions, indicators regarding mental health are also important since it was evident that psychosocial interventions such as social activities have positive effects on quality of life, mental health and reduction of depressive symptoms [7]. For care recipients in the HCBS, apart from the care satisfaction surveys that are commonly conducted on a periodic basis by care providers, the outcome indicators measured in each reassessment remain unexplored. Based on the emphasis on health/ care outcomes to the effectiveness of service delivery, this research sought to explore care recipients' health outcomes and examine the factors influencing changes in outcomes over time for four follow-up visits (i.e., over two years). It is hoped that the outcome evaluations of care recipients on a routine basis would not only add information about the care recipients, but also prove useful with regard to making effective improvements to the practice in LTC.

\section{Methods}

\section{Data source and study design}

The data came from the long-term care dataset (LTC-CM) of Taiwan. Starting in 2008, the dataset has been maintained in each county in which the health indicators of care recipients were recorded in initial needs assessments, as well as the reassessments conducted by care managers during the follow-up process.

\section{Settings and participants}

In this study, we analyzed the long-term care dataset of one southern metropolitan city in Taiwan. Currently, only LTC recipients who receive the Home and Community-based Service (HCBS) noted above are recorded in the dataset, wherein home services are the most common type of services that are used long term. When data for the present study was collected in 2014, a total of 5,675 care recipients aged 50 and over had initial needs assessment (T0) records kept in the dataset. That is, the potential needs of these care recipients were identified through the needs assessment process. Among them, 1,338 had records for reassessment through two years (T4). That is, for the reassessments that were conducted, this study included analyses for four follow-up visits.

Some care recipients were unable to be measured using the Short Portable Mental Status Questionnaire (SPMSQ) $(n=1030)$ and the short version of the Centre for Epidemiologic Studies Depression Scale (CESD) $(\mathrm{n}=1098)$ in the LTC dataset. It was found that there were some differences between the two types of recipients with missing data, mainly occurring among those with high dependency. For the analyses of outcome changes, we included primary respondents who did not respond through a proxy and remained in the HCBS for two years from the baseline. The study protocol (No: A-ER-102017) was also approved, and no conflicts interest existed between the authors and the goals of this study.

\section{Measures}

For each needs assessment and the follow-up monitoring, a nationwide standardized assessment questionnaire, as mentioned previously, is used by care managers to evaluate their clients' physical, psychological, and social aspects of health, in order to identify their long-term care needs, and thus to modify the subsequent care plan as needed. Apart from the care recipients' socio-demographic characteristics, four universal health outcome measures available in the dataset were analyzed, including the activities of daily living (ADLs), the instrumental activities of daily living (IADLs), and the Short Portable Mental Status Questionnaire (SPMSQ; in the need assessment questionnaire, scores of 1 to 4 ranging from severe cognitive impairment to no cognitive problem, respectively, were assigned after adjusting for the educational levels), and the short version of the Centre for Epidemiologic Studies Depression Scale (CESD; scores $\geq 12$ for males and $\geq 10$ for females indicated depressive tendency) used in the assessment questionnaire.

\section{Data analyses}

The data analyses for the study included descriptive and inferential statistics. A description of the study samples and univariate analyses between independent variables and dependent variables were first conducted. Secondly, for the follow-up outcome measures of care recipients, Generalized Estimating Equations (GEE) were used to examine the potential associations between the available health outcome measures of the four follow-up time points (T1-T4) and the 
dependency levels at T0, as well as the socio-demographic variables of clients, including age, gender, education, living status, social welfare status and financial means. Each test of the model parameters was twosided and compared with the control at the 0.05 level of significance. All analyses were performed using SPSS version 17.0.

\section{Results}

\section{The characteristics of care recipients at baseline (T0)}

There were 2,610 (46.0\%), 1,117 (19.7\%) and 1,948 (34.3\%) persons identified as being in the high dependency (HD), moderate dependency (MD) and low dependency (LD) groups at baseline. Table 1 shows the socio-demographic and health characteristics for care recipients at baseline (T0) $(\mathrm{n}=5,675)$ and the samples who were followed to T4 $(\mathrm{n}=1,338)$. It was found that the characteristics of age, living status, financial means, and household social welfare status were significantly different, and there were also some differences among the health status and dependency levels between the two samples.

\section{The health outcome changes of the care recipients from T0-T4}

In terms of outcome changes, data for 1,338 care recipients who had an initial need assessment (T0) and were evaluated four times (T4) were analyzed. The mean changes of ADLs were from 54.77(T0) to 55.68 (T4). The scores of IADLs changed significantly from 9.69 (T0) to 7.23 (T4). The SPMSQ score changed from 3.52 (T0) to 3.46 (T4) while the CESD changed significantly from 7.67 (T0) to 7.27 (T4). It was found that there were significant changes for some health indicators from T0 to T4, especially the IADL scores and CESD scores.

\section{The predictors of outcome changes from T0-T4}

In this study, the health outcome changes were examined by GEE analysis. The four commonly used outcome measures (dependent variables) included functional disabilities (measured in terms of ADLs and IADLs), cognitive status (as measured by the SPMSQ), and depression (as measured by the CESD) in the LTC-CM dataset. The independent variables were care recipients' socio-demographic characteristics and the variable of dependency level at baseline, while the dependent variables for each outcome were also measured. Tables 2 to 5 showed the details of the results, and the coefficients and odds ratios of the covariates (independent variables) related to the outcome variables were also presented.

The dependency levels at T0 influenced the health outcome changes: The results showed that, in general, the dependency levels at T0 significantly influenced the health outcome changes. When using the LD group as a reference, it is clear that for the outcome variables of ADLs, IADLs and SPMSQ, the MD and HD groups were more likely to have worse outcome changes with negative estimates (for ADLs: $\mathrm{OR}=0.246$ for $\mathrm{MD}, 0.010$ for $\mathrm{HD}, p<0.01$; for IADLs: $\mathrm{OR}=0.335$ for $\mathrm{MD}, 0.079$ for HD, $p<0.001$; for SPMSQ: OR=0.642 for MD, $p<$ 0.01 ; 0.391 for HD, $p<0.001$ ), meaning that the lower the scores, the worse the outcome changes. The CESD scores also showed that worse outcome changes in the MD and HD groups with positive estimates (for CESD: $\mathrm{OR}=1.808$ for $\mathrm{MD}, 1.825$ for $\mathrm{HD}$, respectively, $p<0.01$ ), since the higher the CESD scores, the worse the outcomes.

The changes in health outcomes from T0 to T4: Since the changes in health outcomes from $\mathrm{T} 0$ to $\mathrm{T} 4$ were the primary focus of this study, the results showed that when controlling for all other factors, the scores of ADLs increased from T1-T3 (OR ranging from 1.27, 1.25 to $1.21, p<0.01$ ), while the scores at T4 were no more significant when
Table 1. The comparison of all long-term care recipients receiving services at baseline (T0) versus those that have full follow up to two years (T4). Note: $\mathrm{N}=5,675$ at baseline (with the initial needs assessment at T0); $\mathrm{N}=1,338$ for those finishing four times' follow-up (T0-T4).

\begin{tabular}{|c|c|c|c|c|}
\hline & \multicolumn{2}{|c|}{ Total $(N=5675)$} & \multicolumn{2}{|c|}{ Total $(\mathrm{N}=1338)$} \\
\hline & N/Mean & $\% /$ SD & N/Mean & $\% /$ SD \\
\hline \multicolumn{5}{|c|}{ Socio-Demographic Characteristics } \\
\hline Age & 77.02 & 10.054 & 76.06 & 10.231 \\
\hline \multicolumn{5}{|l|}{ Gender } \\
\hline Male & 2342 & 41.3 & 551 & 41.2 \\
\hline Female & 3333 & 58.7 & 787 & 58.8 \\
\hline \multicolumn{5}{|l|}{ Living status } \\
\hline $\begin{array}{l}\text { Co-residency } \\
\text { with others }\end{array}$ & 3217 & 56.7 & 589 & 44.0 \\
\hline $\begin{array}{l}\text { With spouse } \\
\text { only }\end{array}$ & 1168 & 20.6 & 395 & 29.5 \\
\hline Alone & 1223 & 21.6 & 308 & 23.0 \\
\hline Missing & 67 & 1.2 & 46 & 3.4 \\
\hline \multicolumn{5}{|l|}{ Education } \\
\hline Illiterate & 2790 & 49.2 & 682 & 51.0 \\
\hline $\begin{array}{l}\text { literate/primary } \\
\text { school }\end{array}$ & 1773 & 31.2 & 382 & 28.6 \\
\hline $\begin{array}{l}\text { Junior high and } \\
\text { above }\end{array}$ & 1107 & 19.5 & 270 & 20.2 \\
\hline Missing & 5 & 0.1 & 4 & 0.3 \\
\hline \multicolumn{5}{|l|}{ Financial means } \\
\hline $\begin{array}{l}\text { From children } \\
\text { only }\end{array}$ & 2124 & 37.4 & 372 & 27.8 \\
\hline $\begin{array}{l}\text { From social } \\
\text { welfare } \\
\text { subsidies }\end{array}$ & 2452 & 43.2 & 716 & 53.5 \\
\hline $\begin{array}{l}\text { From pensions } \\
\text { of retirement }\end{array}$ & 997 & 17.6 & 215 & 16.1 \\
\hline Missing & 102 & 1.8 & 35 & 2.6 \\
\hline
\end{tabular}

Household social welfare status

\begin{tabular}{|l|c|c|c|c|}
\hline $\begin{array}{l}\text { Non low-income } \\
\text { households }\end{array}$ & 3811 & 67.2 & 786 & 58.7 \\
\hline
\end{tabular}

\begin{tabular}{|l|l|l|l|l|}
\hline Mid low-income & 763 & 13.4 & 259 & 19.4 \\
\hline
\end{tabular}

households

Low-income households

Missing

Dependency Levels

\begin{tabular}{|l|l|l|l|l|}
\hline HD & 2610 & 46.0 & 666 & 49.8 \\
\hline MD & 1117 & 19.7 & 281 & 21.0 \\
\hline LD & 1948 & 34.3 & 391 & 29.2 \\
\hline
\end{tabular}

\begin{tabular}{|l|}
\hline LD \\
\hline Health Outcome
\end{tabular}

\begin{tabular}{|l|c|c|c|c|}
\hline ADL score & $\mathbf{5 6 . 9 4}$ & $\mathbf{3 2 . 1 6}$ & $\mathbf{5 4 . 7 7}$ & $\mathbf{3 1 . 1 9}$ \\
\hline $0-30: 0$ & 1517 & 26.7 & 369 & 27.6 \\
\hline$\geq 31: 1$ & 4158 & 73.3 & 969 & 72.4 \\
\hline IADL score & $\mathbf{8 . 0 0}$ & $\mathbf{6 . 6 8}$ & $\mathbf{9 . 6 9}$ & $\mathbf{7 . 6 3}$ \\
\hline 0-8: 0 & 3417 & 60.2 & 705 & 52.7 \\
\hline$\geq 9: 1$ & 2258 & 39.8 & 633 & 47.3 \\
\hline SPMSQ score & $\mathbf{3 . 4 6}$ & $\mathbf{0 . 8 8}$ & $\mathbf{3 . 5 2}$ & $\mathbf{0 . 8 3}$ \\
\hline $\begin{array}{l}\text { cognitive } \\
\text { impairment: } 0\end{array}$ & 1480 & 26.1 & 325 & 24.3 \\
\hline $\begin{array}{l}\text { no cognitive } \\
\text { problem: } 1\end{array}$ & 3165 & 55.8 & 796 & 59.5 \\
\hline Missing & 1030 & 18.1 & 217 & 16.2 \\
\hline CESD score & $\mathbf{6 . 9 2}$ & $\mathbf{2 . 8 6}$ & $\mathbf{7 . 6 7}$ & $\mathbf{3 . 1 2}$ \\
\hline NO: 0 & 4036 & 71.1 & 909 & 67.9 \\
\hline YES: 1 & 541 & 9.5 & 207 & 15.5 \\
\hline Missing & 1098 & 19.3 & 222 & 16.6 \\
\hline
\end{tabular}


compared with T0. That is, it is more likely to have significantly better changes in outcome with positive estimates for ADLs in the first 18 months (Table 2). Regarding the scores of IADLs, it is clear that these decreased significantly from six months (T1) to the two-year followup time point (T4) (OR from T1-T4=0.75 to $0.66, p<0.001$ ). That is, the outcomes changed negatively for IADLs (Table 3 ). The scores of SPMSQ also decreased significantly at T4 when compared with T0 $(\mathrm{OR}=0.85, p<0.01)$, and thus the average cognitive status (SPMSQ) changed negatively (Table 4 ). In contrast, the CESD outcomes changed positively (OR from T1-T4=0.73 to $0.55, p<0.001$ ) when using no depressive tendency as the reference.

The influences of socio-demographic factors on health outcomes: In addition, some socio-demographic factors showed significant estimates when compared with the reference group of each variable, as shown in Tables 2 to 5. Apart from the time of needs assessments, in general, age, gender, living status, education level, financial means and household social welfare status were significantly associated with changes in the score for the outcome variables. For example, age had a significant and negative path estimate on changes in the score for IADLs (OR=0.97, $p<0.001$ ) and SPMSQ (OR=0.96, $p<0.001$ ), while age had no significant influence on changes in the score for ADL. With increasing age there was also a negative path estimate on the change in score for CESD $(\mathrm{OR}=0.98, p<0.05)$, and this is a positive outcome change, since a higher score means a worse outcome on the CESD. Female was positively associated with changes in the IADLs score $(\mathrm{OR}=1.42, p<0.01)$. It was also positively associated with changes in

Table 2. Predictors of ADLs scores among the recipients in HCBS (GEE regressions). Note: Sample Size: $\mathrm{N}=6,520$ (excluded=170). GEE stands for generalized estimation equation. " $p$ $<0.05 ;{ }^{* * *} p<0.01 ;{ }^{* * *} p<0.001$.

\begin{tabular}{|c|c|c|c|c|}
\hline \multirow{2}{*}{ Variables } & \multirow[b]{2}{*}{$\widehat{\boldsymbol{\beta}}$} & \multirow[b]{2}{*}{$\operatorname{Exp}(\tilde{\beta})$} & \multicolumn{2}{|c|}{ 95\% Wald Confidence Interval } \\
\hline & & & Lower & Upper \\
\hline \multicolumn{5}{|c|}{ Times of needs assessment (ref. T0) } \\
\hline $\mathrm{T} 1$ & $0.239^{* * *}$ & $1.270^{* * *}$ & 1.149 & 1.405 \\
\hline $\mathrm{T} 2$ & $0.222^{* * *}$ & $1.249^{* * *}$ & 1.108 & 1.408 \\
\hline $\mathrm{T} 3$ & $0.191^{* *}$ & $1.210^{* *}$ & 1.056 & 1.386 \\
\hline $\mathrm{T} 4$ & 0.105 & 1.110 & 0.958 & 1.287 \\
\hline Age & 0.009 & 1.009 & 0.995 & 1.023 \\
\hline \multicolumn{5}{|c|}{ Gender (ref. Male) } \\
\hline Female & 0.146 & 1.157 & 0.863 & 1.550 \\
\hline \multicolumn{5}{|c|}{ Living status (ref. With others) } \\
\hline $\begin{array}{l}\text { With spouse } \\
\text { only }\end{array}$ & 0.189 & 1.208 & 0.961 & 1.517 \\
\hline Alone & $1.410^{* * *}$ & $4.097^{* * *}$ & 2.585 & 6.494 \\
\hline \multicolumn{5}{|c|}{ Education (ref. illiterate) } \\
\hline $\begin{array}{c}\text { Literate/Primary } \\
\text { school }\end{array}$ & -0.024 & 0.976 & 0.711 & 1.340 \\
\hline $\begin{array}{l}\text { High school and } \\
\text { above }\end{array}$ & 0.064 & 1.066 & 0.723 & 1.572 \\
\hline \multicolumn{5}{|c|}{ Financial means (ref. From children only) } \\
\hline $\begin{array}{l}\text { From social } \\
\text { welfare } \\
\text { subsidies }\end{array}$ & 0.207 & 1.230 & 0.964 & 1.568 \\
\hline $\begin{array}{c}\text { From pensions } \\
\text { of retirement }\end{array}$ & -0.090 & 0.914 & 0.649 & 1.287 \\
\hline \multicolumn{5}{|c|}{ Household social welfare status (ref. Non-low-income households) } \\
\hline $\begin{array}{c}\text { Mid low-income } \\
\text { households }\end{array}$ & -0.183 & 0.832 & 0.674 & 1.029 \\
\hline $\begin{array}{l}\text { Low-income } \\
\text { households }\end{array}$ & 0.002 & 1.002 & 0.767 & 1.311 \\
\hline \multicolumn{5}{|c|}{ Dependency level (ref. LD) } \\
\hline MD & $-1.400^{* *}$ & $0.246^{* *}$ & 0.101 & 0.602 \\
\hline HD & $-4.635^{* * *}$ & $0.010^{* * * *}$ & 0.004 & 0.022 \\
\hline
\end{tabular}

Table 3. Predictors of IADLs scores among the recipients in HCBS (GEE regressions). Note: Sample Size: $\mathrm{N}=6,520$ (excluded=170). GEE stands for generalized estimation equation. " $p<0.05 ;{ }^{* *} p<0.01 ;{ }^{* * *} p<0.001$. IADL: score ranging from $0-24$. IADLs score $0-8$ : 0 (as the reference group); $\geq 9: 1$.

\begin{tabular}{|c|c|c|c|c|}
\hline \multirow{2}{*}{ Variables } & \multirow[b]{2}{*}{$\widehat{\beta}$} & \multirow[b]{2}{*}{$\operatorname{Exp}(\tilde{\beta})$} & \multicolumn{2}{|c|}{ 95\% Wald Confidence Interval } \\
\hline & & & Lower & Upper \\
\hline \multicolumn{5}{|c|}{ Times of needs assessment (ref. T0) } \\
\hline $\mathrm{T} 1$ & 0.031 & 1.032 & 0.952 & 1.118 \\
\hline $\mathrm{T} 2$ & -0.035 & 0.965 & 0.870 & 1.071 \\
\hline $\mathrm{T} 3$ & -0.080 & 0.924 & 0.828 & 1.030 \\
\hline $\mathrm{T} 4$ & $-0.161^{* *}$ & $0.852^{* * *}$ & 0.756 & 0.959 \\
\hline Age & $-0.038^{* * *}$ & $0.962^{* * *}$ & 0.949 & 0.976 \\
\hline \multicolumn{5}{|c|}{ Gender (ref. Male) } \\
\hline Female & -0.094 & 0.910 & 0.698 & 1.186 \\
\hline \multicolumn{5}{|c|}{ Living status (ref. With others) } \\
\hline $\begin{array}{l}\text { With spouse } \\
\text { only }\end{array}$ & 0.184 & 1.201 & 0.972 & 1.486 \\
\hline Alone & $0.471^{* * *}$ & $1.602^{* * * *}$ & 1.269 & 2.021 \\
\hline \multicolumn{5}{|c|}{ Education (ref. illiterate) } \\
\hline $\begin{array}{c}\text { Literate/Primary } \\
\text { school }\end{array}$ & $0.500^{* *}$ & $1.649^{* *}$ & 1.225 & 2.221 \\
\hline $\begin{array}{c}\text { High school and } \\
\text { above }\end{array}$ & $0.551^{* *}$ & $1.735^{* *}$ & 1.219 & 2.467 \\
\hline \multicolumn{5}{|c|}{ Financial means (ref. From children only) } \\
\hline $\begin{array}{l}\text { From social } \\
\text { welfare } \\
\text { subsidies }\end{array}$ & $0.248^{*}$ & $1.281^{*}$ & 1.050 & 1.563 \\
\hline $\begin{array}{c}\text { From pensions } \\
\text { of retirement }\end{array}$ & $0.371^{* *}$ & $1.450^{* *}$ & 1.106 & 1.899 \\
\hline \multicolumn{5}{|c|}{ Household social welfare status (ref. Non-low-income households) } \\
\hline $\begin{array}{c}\text { Mid low-income } \\
\text { households }\end{array}$ & 0.037 & 1.038 & 0.875 & 1.231 \\
\hline $\begin{array}{l}\text { Low-income } \\
\text { households }\end{array}$ & 0.038 & 1.039 & 0.851 & 1.268 \\
\hline \multicolumn{5}{|c|}{ Dependency level (ref. LD) } \\
\hline MD & $-0.443^{* *}$ & $0.642^{* *}$ & 0.459 & 0.897 \\
\hline HD & $-0.938^{* * *}$ & $0.391^{* * *}$ & 0.291 & 0.526 \\
\hline
\end{tabular}

the CESD score $(\mathrm{OR}=5.55, p<0.001)$, meaning that women had greater odds of having a depressive tendency. Living alone showed a positive relationship with ADLs (OR=4.10, $p<0.001)$, IADLs $(\mathrm{OR}=2.07, p<$ $0.001)$, and SPMSQ scores $(\mathrm{OR}=1.60, p<0.001)$. Higher educational levels showed a positive relationship with IADLs $(\mathrm{OR}=1.61$ and 2.05 , respectively, $p<0.01)$ and SPMSQ scores $(\mathrm{OR}=1.65$ and 1.74 , respectively, $p<0.01$ ), while they had no significant relationship with CESD (Table 5). It was also found that financial means and household social welfare status were predictors of the care recipients' outcomes. For example, when comparing those with support from children only, those with sufficient financial means mainly from social welfare subsidies and from pensions were more likely to have positive estimates on the change in score of the SPMSQ (OR=1.28 and 1.45, respectively, $p<0.05)$. Finally, the household social welfare status showed no significant influence on changes in outcomes in this study.

\section{Discussion}

The goal of long-term care is to maximize independence [8]. Governments need tools to monitor and evaluate the functioning of a long-term care system on a routine basis, and to allow for more informed decisions about health system funding, organization and policies [5]. In considering the development of community care, an important issue is to what extent the related initiatives lead to better outcomes in terms of meeting unmet needs [9]. Although regular accreditations are performed by the government, cross-sectional inputs and outputs remain the focus in Taiwan. To the best of our knowledge, 
Table 4. Predictors of SPMSQ scores among the recipients in HCBS (GEE regressions). Note: Sample Size: $\mathrm{N}=5422$ (excluded=1268). GEE stands for generalized estimation equation. " $p<0.05 ;{ }^{* *} p<0.01 ;{ }^{* * *} p<0.001$. Cognition status was categorized in MDAI as $1-4$ ranging from severe cognitive impairment (1) to no cognitive problem (4). Cognition status was categorized in MDAI as 1-3: 0 (as the reference group); 4: 1.

\begin{tabular}{|c|c|c|c|c|}
\hline \multirow{2}{*}{ Variables } & \multirow[b]{2}{*}{$\widehat{\beta}$} & \multirow[b]{2}{*}{$\operatorname{Exp}(\widehat{\beta})$} & \multicolumn{2}{|c|}{ 95\% Wald Confidence Interval } \\
\hline & & & Lower & Upper \\
\hline \multicolumn{5}{|c|}{ Times of needs assessment (ref. T0) } \\
\hline $\mathrm{T} 1$ & 0.031 & 1.032 & 0.952 & 1.118 \\
\hline $\mathrm{T} 2$ & -0.035 & 0.965 & 0.870 & 1.071 \\
\hline T3 & -0.080 & 0.924 & 0.828 & 1.030 \\
\hline $\mathrm{T} 4$ & $-0.161^{* *}$ & $0.852^{* *}$ & 0.756 & 0.959 \\
\hline Age & $-0.038^{* * *}$ & $0.962^{* * * *}$ & 0.949 & 0.976 \\
\hline \multicolumn{5}{|c|}{ Gender (ref. Male) } \\
\hline Female & -0.094 & 0.910 & 0.698 & 1.186 \\
\hline \multicolumn{5}{|c|}{ Living status (ref. With others) } \\
\hline $\begin{array}{l}\text { With spouse } \\
\text { only }\end{array}$ & 0.184 & 1.201 & 0.972 & 1.486 \\
\hline Alone & $0.471^{* * * *}$ & $1.602^{* * *}$ & 1.269 & 2.021 \\
\hline \multicolumn{5}{|c|}{ Education (ref. illiterate) } \\
\hline $\begin{array}{c}\text { Literate/Primary } \\
\text { school }\end{array}$ & $0.500^{* *}$ & $1.649^{* *}$ & 1.225 & 2.221 \\
\hline $\begin{array}{l}\text { High school and } \\
\text { above }\end{array}$ & $0.551^{* *}$ & $1.735^{* *}$ & 1.219 & 2.467 \\
\hline \multicolumn{5}{|c|}{ Financial means (ref. From children only) } \\
\hline $\begin{array}{l}\text { From social } \\
\text { welfare } \\
\text { subsidies }\end{array}$ & $0.248^{*}$ & $1.281^{*}$ & 1.050 & 1.563 \\
\hline $\begin{array}{c}\text { From pensions } \\
\text { of retirement }\end{array}$ & $0.371^{* *}$ & $1.450^{* *}$ & 1.106 & 1.899 \\
\hline \multicolumn{5}{|c|}{ Household social welfare status (ref. Non-low-income households) } \\
\hline $\begin{array}{l}\text { Mid low-income } \\
\text { households }\end{array}$ & 0.037 & 1.038 & 0.875 & 1.231 \\
\hline $\begin{array}{l}\text { Low-income } \\
\text { households }\end{array}$ & 0.038 & 1.039 & 0.851 & 1.268 \\
\hline \multicolumn{5}{|c|}{ Dependency level (ref. LD) } \\
\hline MD & $-0.443^{* *}$ & $0.642^{* *}$ & 0.459 & 0.897 \\
\hline HD & $-0.938^{* * *}$ & $0.391^{* * *}$ & 0.291 & 0.526 \\
\hline
\end{tabular}

the health outcomes of care recipients in the LTC-CM dataset have received little attention or follow-ups analyses. In order to continue and improve the home and community-based service (HCBS), there is a need to observe the follow-up health outcomes of care recipients and provide feedback on the effects of the current provision of the HCBS system and LTC policymaking. Based on the results of this study, key findings that require further attention are discussed in the following sections.

\section{Who were the users in HCBS?}

Among the HCBS in Taiwan, home services are used more often and on a longer-term base than other services [1]. It was not surprising that old age was associated with life course functional decline and cognitive impairments $[10,11]$. It was also found that women were more likely to need LTC (nearly 60\%) than men, and this was in line with the findings of previous research. For example, for elderly people in Taiwan, previous research found that females were more likely to be in the frail and functionally impaired group [12]. A report about LTC in OECD countries indicated that about $61 \%$ of all LTC users were women [13]. Doblhammer and Hoffmann also found a higher prevalence of disability in women [14]. A recent time trends study in Sweden also showed that ADL disability had increased in women but not in men [15].

The LTC policy in Taiwan is a social welfare policy and the program aims to take care of more disadvantaged elderly people. For example, elderly people living alone can get LTC services even if they only have difficulty with IADLs. Moreover, those care recipients from mid-low or low-income households have smaller or even no co-payments. The care recipients in the HCBS have thus been selected by the care management system, and the details of their profiles are decided based on this.

However, the results of this study showed that the sociodemographic characteristics of those who stayed for two years were somewhat different from those with initial needs assessments. Apart from age, more of those living alone and with a spouse only stayed in the HCBS. The care recipients were also those with financial means that was mainly obtained from social welfare subsidies, and those from low and mid-low-income households. In terms of health status and dependency level, it was found that those with less physical disabilities but more depressive symptoms stayed with the HCBS for longer. It is important to understand the health status of the individuals involved at each follow-up time point. However, the care monitoring of LTC recipients is yet not very thorough, and feedback information about health outcomes has not required being analyzed as parts of the system's standard practices. As such, the issues related to unmet need and care quality in terms of outcome changes mostly remain unexplored.

\section{The different outcome changes in two years}

Physical health outcomes-ADLs and IADLs: In this study, the health indicators of ADLs showed positive outcome changes among

Table 5. Predictors of CESD scores among the recipients in HCBS (GEE regressions). Note: Sample Size: $\mathrm{N}=5347$ (excluded=1343). GEE stands for generalized estimation equation. " $p<0.05 ;{ }^{* * *} p<0.01 ;{ }^{* * * *} p<0.001$. CESD: Scores were ranging from $0-20$. The higher scores, the worse condition of depressive tendency. The thresholds of depressive tendency (coding: 1): male $\geq 12$, female $\geq 10$ according to the standard in LTC 1.0 plan and no depressive tendency: 0 as the reference group.

\begin{tabular}{|c|c|c|c|c|}
\hline \multirow{2}{*}{ Variables } & \multirow[b]{2}{*}{$\hat{\beta}$} & \multirow[b]{2}{*}{$\operatorname{Exp}(\widehat{\beta})$} & \multicolumn{2}{|c|}{ 95\% Wald Confidence Interva } \\
\hline & & & Lower & Upper \\
\hline \multicolumn{5}{|c|}{ Times of needs assessment (ref. T0) } \\
\hline $\mathrm{T} 1$ & $-0.319^{* * * *}$ & $0.727^{* * * *}$ & 0.634 & 0.834 \\
\hline $\mathrm{T} 2$ & $-0.386^{* * *}$ & $0.680^{* * *}$ & 0.582 & 0.794 \\
\hline $\mathrm{T} 3$ & $-0.439^{* * *}$ & $0.645^{* * *}$ & 0.538 & 0.772 \\
\hline $\mathrm{T} 4$ & $-0.598^{* * *}$ & $0.550^{* * *}$ & 0.448 & 0.675 \\
\hline Age & $-0.019^{*}$ & $0.982^{*}$ & 0.966 & 0.998 \\
\hline \multicolumn{5}{|c|}{ Gender (ref. Male) } \\
\hline Female & $1.715^{* * *}$ & $5.554^{* * *}$ & 3.736 & 8.258 \\
\hline \multicolumn{5}{|c|}{ Living status (ref. With others) } \\
\hline $\begin{array}{l}\text { With spouse } \\
\text { only }\end{array}$ & 0.175 & 1.191 & 0.876 & 1.620 \\
\hline Alone & 0.060 & 1.062 & 0.744 & 1.515 \\
\hline \multicolumn{5}{|c|}{ Education (ref. illiterate) } \\
\hline $\begin{array}{c}\text { Literate/Primary } \\
\text { school }\end{array}$ & -0.087 & 0.917 & 0.649 & 1.295 \\
\hline $\begin{array}{l}\text { High school and } \\
\text { above }\end{array}$ & -0.243 & 0.784 & 0.494 & 1.244 \\
\hline \multicolumn{5}{|c|}{ Financial means (ref. From children only) } \\
\hline $\begin{array}{l}\text { From social } \\
\text { welfare } \\
\text { subsidies }\end{array}$ & 0.225 & 1.253 & 0.912 & 1.720 \\
\hline $\begin{array}{c}\text { From pensions } \\
\text { of retirement }\end{array}$ & 0.106 & 1.111 & 0.758 & 1.629 \\
\hline \multicolumn{5}{|c|}{ Household social welfare status (ref. Non-low-income households) } \\
\hline $\begin{array}{l}\text { Mid low-income } \\
\text { households }\end{array}$ & 0.190 & 1.209 & 0.908 & 1.610 \\
\hline $\begin{array}{l}\text { Low-income } \\
\text { households }\end{array}$ & 0.236 & 1.266 & 0.939 & 1.707 \\
\hline \multicolumn{5}{|c|}{ Dependency level (ref. LD) } \\
\hline MD & $0.592^{* *}$ & $1.808^{* *}$ & 1.212 & 2.697 \\
\hline HD & $0.602^{* *}$ & $1.825^{* *}$ & 1.264 & 2.636 \\
\hline
\end{tabular}


the care recipients. More specifically, the ADLs scores increased for up to 18 months when controlling for the respondents' dependency levels and socio-demographic factors at baseline. It is suggested that for the care recipients the current HCBS seems to work well in meeting their physical needs.

For IADLs, however, negative outcome changes were found for all care recipients over time, and women were found to have greater falls in scores than men. An explanation for this may be that most of the household chores and errands were taken care of by relatives rather than the care recipients, or maybe that it was not easy to distinguish between a lack of the ability to do such tasks and the lack of any need to do so in the short reassessment visit. However, previous research in Canada found that difficulties with IADLs were related to have the highest prevalence of unmet/under met needs for long-term care [16]. Access to basic amenities in the home was also found to be the first key determinant of quality of life and self-esteem among Asian disabled people [17]. Moreover, IADL disability was found to be a significant predictor of cognitive impairment of elderly people in Taiwan [18]. IADLs serve as an important outcome measure, and if the provision of current HCBS, especially in-home services, existed the gap to match the needs of those with difficulties in IADLs, then this issue needed to be addressed. This also reminds us that some services in the current HCBS may also need to be innovated or improved upon [17].

Mental health outcomes - Cognition and Depression: In this study, the health indicators of the SPMSQ showed negative outcome changes among the care recipients over two years for those with available data.

Regarding the follow-up outcome changes, our findings were in accord with previous research. For example, a study of veterans in Taiwan found that poor physical function and the presence of resident assessment protocol triggers for cognitive loss/dementia were strong predictors of cognitive decline [19]. Another research focused on participants in institutions and in day-care centers, in which they found that the majority of participants had a mild-to-moderate cognitive impairment at baseline, and revealed a similar global cognitive decline rate $[20,21]$. However, the mean age in the earlier study was higher (ranging from 81-86 years old) than the mean age in our study (7677 years old). So, there may exist the gap in the current HCBS to fill in more psychological care and support needs to be further examined.

In our research, in contrast, CESD scores were found to have positive outcome changes among the care recipients for up to two years, which showed development in a different direction than the SPMSQ. Previous research mentioned the relationship between cognitive status and depressive symptoms, and their associations with functional decline $[22,23]$ and this is of clinical and public health relevance, as it appears to be the common link. A US national prospective study for a cohort of older people (mean age 77) found that among participants with dependence in ADLs at baseline, cognitive impairment, but not depressive symptoms, was a risk factor for the additional decline [24]. They found that, in fact, subjects with depressive symptoms, on average, demonstrated a slight improvement in ADLs function. Another research found that for individuals with above average functional limitations, receipt of formal and informal support was associated with fewer depressive symptoms. The authors thus suggested that receiving a combination of informal and formal support may be sufficient to offset the harmful association between disability and depressive symptoms in later life [25]. Therefore, the fact that the care recipients with a disability were found to have better outcome changes on the
CESD in our study may be related to the stress-buffering effects, but further research is needed to address this possibility.

Statistics from 1984 to 1994 in the US showed that the prevalence of cognitive impairment rose over the decade [26]. In contrast, the prevalence of functional limitations (upper and lower body difficulties) and difficulties with seeing and communicating remained virtually unchanged. It seems that more focus on psychological needs is critical to match the increasing need for long-term care. In viewing the current HCBS in the LTC system, it is apparent that less psychological support is made available than would be ideal. Current services seem more focused on vulnerable care recipients with difficulties in ADLs, as well as those who were single, living alone, and/or living in low-income households, since these were the characteristics more easily detected than complicated multiple needs factors, especially psychological ones [27] With the different changes in outcomes that were found between the SPMSQ and CESD, there remains a need for more research from the provision of professional consultations and help for LTC recipients. It was found depressive symptoms could be improved, especially if effective treatment is administered [24]. Prior research also reminded us that the diagnosis of dementia and depression remained lower than expected among the elderly population [26].

As mentioned in previous research, Asian countries have not reported evidence for compression of morbidity [28] and $\mathrm{Ku}$, Liu and Wen [29] carried out a study in Taiwan found that the trend in having at least one of the six ADL limitations among communitydwelling elderly people increased mildly in the past decade. The use of community services also increased over this period, not because of widespread substitution of community care for nursing home care, but because of increased use among those in the community [30]. The population with LTC needs is rapidly increasing in Taiwan, and it is thus necessary to continue to develop and provide HCBS which could match LTC needs with good quality services. Since the service delivery of HCBS in the LTC system is based on the care management system in Taiwan, it is important how the care managers function as coordinators to deliver right LTC services, including planning visits for needs assessment and service monitoring, as well as promoting interdisciplinary team practices, as such steps are critical to obtaining the feedback needed to improve the system.

\section{Limitations}

This study has the following limitations. Firstly, only long-term care recipients receiving home and community-based care/services were reported and recorded in the LTC dataset. Secondly, in practice the health outcomes of care recipients would also be influenced by caregiving in the family network, such as being taken care of by family members and/or informal paid help, since in Taiwan families remain crucial support networks and elder care remains a family responsibility. Thirdly, the follow-up outcomes were chosen based on the available health measurements, including physical (in terms of ADLs and IADLs) and mental outcomes (as measured by the SPMSQ and CESD), whereas outcomes regarding social health, such as social network and environment, were not included since these questions were not on a scale basis, and thus not easy to compare objectively. In addition, since the focus of this study was on LTC recipients, those measurements related to the caregivers were not included. Therefore, the social health and the caregivers' view of health/care outcomes can be further addressed qualitatively and/or included in the future. Finally, since the nationwide LTC dataset has yet been formally released, the samples used in the study came from the LTC dataset of one southern 
city in Taiwan, and thus the generalization of these findings should be handled with caution when considering geographical differences, such as LTC service resources and supply.

\section{Conclusions}

The shortage of research about the effectiveness of interventions has hindered the development of appropriate evidence-based policies and practice in long-term care. In viewing the importance of health outcomes, this research examined the users' profiles last for two years and found that patterns of changes in outcomes. While the IADLs and SPMSQ scores declined with various dependency levels, the ADLs and CESD scores were found to have better outcomes. To reach the goal of HCBS, regular and exact monitoring of care recipients is crucial, while feedback with regard to health outcomes and a greater focus on providing needs-led and responsive services in the community are also required. In the ongoing process of providing long-term care services, such efforts would provide not only more information regarding the care recipients, but also allow for more informed decisions about what to input in order to improve service delivery.

\section{Acknowledgement}

This study received financial support from the Research Centers for Humanities and Social Sciences, National Cheng Kung University (Project number: H101-A304; F101037). We also thank the Bureau of Social Affairs of the local government for helpful consultations with the LTC dataset and Nova Editing is acknowledged for providing editorial assistance in manuscript preparation.

\section{References}

1. Ministry of the Interior (2007) Ten-year Long-Term Care Project (TLTCP).

2. Hutt R, Rosen R, Macauley J (2004) Case managing long term conditions: What impact does it have in the treatment of older people? King's Fund.

3. National Long-Term Care Service Framework (2013) Long Term Care Network Project (Phase I)-102 years to 105 years (in Chinese).

4. California Mental Health Planning Council (2010) Performance indicators for evaluating the mental health system. Performance Indicators.

5. Kruk ME, Freedman LP (2008) Assessing health system performance in developing countries: a review of the literature. Health policy 85: 263-276.

6. Working Group on Health Outcomes for Older Persons with Multiple Chronic Conditions (2012) Universal health outcome measures for older persons with multiple chronic conditions. J Am Geriatr Soc 60: 2333

7. Forsman AK, Nordmyr J, Wahlbeck K (2011) Psychosocial interventions for the promotion of mental health and the prevention of depression among older adults. Health Promot Int 26(suppl 1): i85-i107.

8. Evashwick C (2005) The continuum of long-term care: Cengage Learning. ( $3^{\text {rd }}$ Edn) Medicine \& Health Sciences.

9. Means R, Richards S, Smith R (2008) Community care: policy and practice. Palgrave, Macmillan education.

10. Lipnicki DM, Sachdev PS, Crawford J, Reppermund S, Kochan NA, et al. (2013) Risk factors for late-life cognitive decline and variation with age and sex in the Sydney Memory and Ageing Study. PLoS One 8: e65841. [Crossref]

11. Steptoe A, Deaton A, Stone AA (2015) Subjective wellbeing, health, and ageing. Lancet 385: 640-648. [Crossref]
12. Chen DR, Chang LY, Yang ML (2008) Gender-specific responses to social determinants associated with self-perceived health in Taiwan: A multilevel approach. Social Science \& Medicine 67: 1630-1640.

13. Francesca C, Ana LN, Jérôme M, Frits T (2011) OECD health policy studies help wanted? Providing and paying for long-term care: providing and paying for long-term care. OECD Publishing.

14. Doblhammer G, Hoffmann R (2010) Gender differences in trajectories of health limitations and subsequent mortality. A study based on the German Socioeconomic Panel 1995-2001 with a mortality follow-up 2002-2005. The Journals of Gerontology 65: 482-491.

15. Sjölund BM, Wimo A, Qiu C, Engström M, von Strauss E (2014) Time trends in prevalence of activities of daily living (ADL) disability and survival: comparing two populations (aged 78+ years) living in a rural area in Sweden. Archives of gerontology and geriatrics 58: 370-375.

16. Keefe J, Vézina S, Spin P (2012) Older Canadian who go without: predictors of unmet need for activities of daily living. European Population Conference, Stockholm University, Sweden pp. 13-16.

17. Vernon A (2002) User-defined outcomes of community care for Asian disabled people. Policy Press.

18. Yen CH, Yeh CJ, Wang CC, Liao WC, Chen SC, et al. (2010) Determinants of cognitive impairment over time among the elderly in Taiwan: results of the national longitudinal study. Archives of gerontology and geriatrics 50: S53-S57.

19. Chen LY, Liu LK, Peng LN, Lin MH, Chen LK, et al. (2014) Identifying residents at greater risk for cognitive decline by Minimum Data Set in long-term care settings. Journal of Clinical Gerontology and Geriatrics 5: 122-126.

20. Maseda A, Balo A, Lorenzo-López L, Lodeiro-Fernández L, Rodríguez-Villamil JL, et al. (2014) Cognitive and affective assessment in day care versus institutionalized elderly patients: a 1-year longitudinal study. Clinical interventions in aging 9: 887.

21. Plassman BL, Williams JW, Burke JR, Holsinger T, Benjamin S (2010) Systematic review: factors associated with risk for and possible prevention of cognitive decline in later life. Annals of Internal Medicine 153: 182-193.

22. Fisher KA, Seow H, Brazil K, Freeman S, Smith TF, et al. (2014) Prevalence and risk factors of depressive symptoms in a Canadian palliative home care population: a crosssectional study. BMC Palliat Care 13: 10. [Crossref]

23. Millán-Calenti JC, Tubío J, Pita-Fernández S, Rochette S, Lorenzo T, et al. (2012) Cognitive impairment as predictor of functional dependence in an elderly sample. Archives of gerontology and geriatrics 54: 197-201.

24. Mehta KM, Yaffe K, Covinsky KE (2002) Cognitive impairment, depressive symptoms, and functional decline in older people. Journal of the American Geriatrics Society 50 1045-1050.

25. Chan N, Anstey KJ, Windsor TD, Luszcz MA (2011) Disability and depressive symptoms in later life: the stress-buffering role of informal and formal support. Gerontology 57: 180-189. [Crossref]

26. AHRQ (2012) Long-term care for older adults: A review of home and communitybased services versus institutional care. Agency for Healthcare Research and Quality, U.S. Department of Health \& Human Services.

27. Liu LF, Yao HP (2014) Examining the Need Assessment Process by Identifying the Need Profiles of Elderly Care Recipients in the Ten-Year Long-Term Care Project (TLTCP) of Taiwan. JAMDA 15: 946-954.

28. Martin LG, Zimmer Z, Hurng BS (2011) Trends in late-life disability in Taiwan, 19892007: The roles of education, environment, and technology. Population studies 65: 289-304.

29. Ku LJ, Liu LF, Wen MJ (2013) Trends and determinants of informal and formal caregiving in the community for disabled elderly people in Taiwan. Arch Gerontol Geriatr 56: 370-376. [Crossref]

30. Ministry of the Interior (2010) Report of the senior citizen condition survey 2009

Copyright: $(2017$ Liu LF. This is an open-access article distributed under the terms of the Creative Commons Attribution License, which permits unrestricted use, distribution, and reproduction in any medium, provided the original author and source are credited. 